\title{
The Students Design Abilities Formation in the Process of Independent Work
}

Gulzida F. Magadieva

\author{
Kazan (Volga region) Federal University, 420008, Kazan, Russia. E-mail: gulzida@mail.ru
}

Elena L. Fedotova

Anastasia S. Kosogova

Irkutsk State University, 664003, Irkutsk, Russia

Elena M. Bastrikova

Kazan (Volga region) Federal University, 420008, Kazan, Russia.

Olga E. Shafranova

Amur State University, 675027, Blagoveshchensk, Russia

Oleg L. Podlinyaev

Aleksandr I. Timoshenko

Irkutsk State University, 664003, Irkutsk, Russia

Doi:10.5901/mjss.2015.v6n6s2p491

\section{Abstract}

Modern society, due to intensive technological development, requires from the specialists the specific design abilities, allowing carry out productive actions in uncertain situations. The aim of this article is directed at determining of students' independent work potential in development of design abilities which are demanded by potential employers. The leading approaches to the study of this problem are a competence-based, acme logical and binary approaches allowing in modern educational process to ensure the creative potential of the student. The authors present a model of design skills' formation, including focus, theoretical, substantive, organizational and productive blocks and defining the organization of University students' independent work. This article is intended for educators, researchers, managers of educational organizations who are involved in the design of the disciplines' content and the organization of students' independent work at the University.

Keywords: higher education, design ability, independent work, pedagogical conditions

\section{Introduction}

\subsection{Background}

Project's development, as a way to achieve goals through a planned sequence of actions involves the study and analysis of ideas, their implementation's possibilities, necessary resources, total cost of the project, its design, simulation and implementation. In modern conditions of technical-technological, economic and social state of society, design becomes one of the ways of activity and development in all fields. Technical, informational, educational, and social types of projects are allocated that through thinking and specific steps and actions in a timely manner allow achieve the goals in the field.

\subsection{Status of a problem}

Designing is regarded by the philosophers as one of the mechanisms of culture, as a result of spiritually-transformative activities that promote the implementation of creative ideas (Kagan, 1998; Kolesnikova, 2008). Psychological and 
pedagogical principles of project-based learning are considered in researches of (Matyash \& Volodina, 2011; Retivikh, 2003).

The idea how to form the students' design competence is considered in the works by I. A. Kolesnikova, M. P. Gorchakova-Sibirskaya (2005), V. A. Slastenin, I. F. Isaev \& E. N. Shiyanov (2002, as a rule, connected with designing in construction, products' design, software and others. However, the formation of students' design abilities during their independent work, as a way to achieve the necessary in modern society level of professionalism and culture, was not sufficiently developed in educational research.

\subsection{Research hypothesis}

The project, which is implemented within the framework of students' independent educational activity, involves the organization of project participants' interaction within the established goals and objectives, the implementation of the study, research and problem methods, defines the presence of students' leadership qualities, their capacity for creative self-activity, communication, motivation, commitment, responsibility and other qualities, which are highly demanded on the labor market in any field of study.

The students' design skills are in the development of individual characteristics on mastering the techniques of design in various fields and are determined by the level of their manifestation (reproductive, heuristic and creative levels).

\section{Methodological Framework}

\subsection{Methodological approaches of research}

To develop the students' design abilities the following methodological approaches are used: competency, acme logical, binary together forming the methodological basis of research.

The phenomena of competence and competence-based approach are studied in pedagogy in the works of $\mathrm{V}$. I. Baidenko (2004), I. A. Zimnaya (2006), A. V. Khutorskoy (2003), etc. Realization of the competence approach in education contributes to faster response of the educational system to the demands of the labor market. Competencebased approach, being focused on a new vision of goals and educational results' evaluation, has its requirements to the components of the educational process - the content, pedagogical technologies, monitoring and evaluation. In the aspect of our study, we consider the student's design abilities as a component of his or her competence, reflecting business, personal qualities and his or her personal social position (Slastenin, Isaev \& Shiyanov, 2002).

Acme logical approach (Ananyev, 2001; Abulkhanova-Slavskaya, 2001; Bodalev, 2002; Derkach, 2000), which determines the potential of the individual in achieving of professionally demanded qualities, gives patterns, factors and ways of achieving of students' design abilities. The main focus of acme logical approach is the possibilities and factors in the achievement of the objectives which are defined by the level of productivity of the educational process. Students' project activities organization in accordance with the acme logical approach should be based on possibilities ensuring of self-determination and self-development of educational entities, the formation of the system of professional and moral values, ideals and ethical standards.Education, in its core is binary by nature, because it defines the interaction between teachers and learners in educational activities through government and self-government, teaching and learning, assessment and self-assessment (Andreev, 2003).

Essentially, the binary approach can be defined as a holistic approach to improve teaching and learning, to optimize objectives, criteria, diagnostic tools and technologies, to streamline the process of assessing the education quality, to optimize the diagnosis (self-diagnosis), control (self-control), planned and achieved learning results (Telegina, 2013). Binary approach to the development of students' design abilities in the process of their independent activity is a conceptual framework that offers an innovative model, including analysis of objective and subjective factors and a developed a pedagogical strategy for achieving the necessary level of competences, the definition of relations and communications between project participants and their roles in achieving goals.

\subsection{Methodological principles of students' design abilities formation}

These approaches define the pedagogical principles of students' independent work organization to develop their design abilities:

The principle of science learning is based on the logical relation between the content of science education, the discipline and the developed project. It requires the content of the training to present the trainees scientific facts, 
concepts, laws, theories of all the main sections of the relevant branch of science, and to the possible extent to be approaching to the disclosure of its modern achievements and prospects of development in the future. The principle of science determines the development of trainees ' skills of scientific inquiry, the ability to observe phenomena, record and analyze the results of observation, the ability to conduct scientific argument, to prove their point of view and to use rationally scientific literature.

The principle of novelty, contributes to students' thinking productivity development by violating their knowledge and understanding boundaries, attracting all the abilities and possibilities of their knowledge. Every time new tasks, installations, conditions of the project not only motivate the student to perform various actions, but also contribute to the formation of such quality skills as flexibility, i.e. the ability to "turn on" in the new situation, the ability to function with new material, when this new material is mastered subconsciously.

The situational principle determines the formation of such conditions of the project's implementation in which the student is forced to act out of typical situations and make decisions which affect the achievement of project's objectives. Proposed conditions determine the direction of action of the learner to expand knowledge and increase motivation to do project activities, facilitates the development of independence and responsibility for making decisions.

The principle of the productivity of the project (Kraevski, 2003), causes the personal, educational and professional growth through positive increment of competencies and the formation of new educational products. Educational increment occurs simultaneously with the development of personal qualities, relevant not only the studied field of education but professional type of activity. Independently formulated and achieved goals of the project, action plans, methods and implementation, algorithms, and performance evaluation become important educational results.

The principle of cooperation is manifested in the organization of entity-entity interaction between the teacher and the student, specifying the nature of the relationship and significantly affecting the formation of personal qualities of the student and between students - executors of the project, determining the mechanisms of the commonwealth, complicity, empathy, co-creation and co-management.

\subsection{The potential of students' independent work in their design abilities development}

The modern paradigm of education is focused on the significant increase of students' independent work (about $50 \%$ of training time), that is, the graduate should be able to learn some of the topics to consolidate classroom material, to develop projects.

Students' independent work is interpreted in pedagogical literature ambiguously: as the execution of additional tasks outside the classroom; activities aimed at the assimilation of the curriculum, without direct participation of the teacher; the way of educational activity of students in extracurricular and classroom time individually or in a group under the guidance of the teacher, teaching method (Babanskij, 1995; Pidcasisty, 2005). The authors believe that students' independent work can be defined as the student's performance, based on the organized by the teacher plan or algorithm that determines a student's ability to self-organization, self-reflection and creative self-realization. The activity of the teacher in this aspect turns into organizational management, when the student receives instructions and advices to work independently and passes the main points for the diagnosis of achieving his or her goals.

Federal state educational standards include the organization of students' project work bachelors of technical and technological areas preparation and methods' formation of project activities for formalization, solutions' algorithm development and solutions' implementation of professional orientation tasks. In the competences, the formation of which is stated in the FSES, in this aspect abilities to apply modern scientific research methods, to develop projects that use information and communication technologies in solving professional problems are allocated. Harmonization of the objectives in bachelors' training for their future work in a manufacturing or scientific field determines the level of their design abilities as the basis of professional competence.

In this paper the following classification of students' independent work is proposed, aimed at the development of their design abilities:

- according to the method of cognition: theoretical or experimental;

- by interaction: group or individual;

- by type of task: reproductive, search, creative, research;

- $\quad$ by subject area: subject or integrated;

- by time of implementation: short term, midterm and long term.

Each of the types of work is aimed at the formation of the specified component of students' design abilities. 


\section{Results}

\subsection{Components' definition of students design abilities}

The components' analysis of students' project work identified in the SFES, involves learning, training and organization of experience in creating concepts for projects, assignments for their development, leadership and organization of the design process, evaluating the quality and efficiency, capacity of implementing the projects in various fields. In modern conditions the design is a means of creating the design method of interaction with the world, removing technological contradictions of the modern stage of social development in general and education in particular (Zimnaya, 2006; Matyash \& Volodina, 2011).

Under the students' design abilities we understand the ability to independent theoretical and practical activity on the development and implementation of projects in various fields of science and social practice, which constitute the basis of professional competence.

The authors identify the following components of the students' design abilities:

- problem-practical - the recognition and understanding of design tasks, adequate setting of goals and objectives, their implementation, i.e. the methods, design algorithms, design methods, modeling methods, methods of evaluating of the project's effectiveness;

- content-practical - understanding of the task from the standpoint of the subject area knowledge, assessment of the feasibility of the project, the search for ways of its decision, the choice of information sources;

- operational - design of new information based on available data through existing skills and experience in the design, practical implementation of the project;

- reflective - evaluation of the project, its essence, goals, objectives and norms from the point of view of perspective of private and universally valid values.

Each component may be formed on one of the levels:

For empirical research three levels of design abilities' manifestation were developed. Reproductive level includes basic (performance) students' possibilities for the project implementation, allowing carry out the planned actions on the given samples.

The heuristic level of abilities involves the ability of a student to influence the development of the project, to search for solutions. Creative level means active manifestation, the activities not only according the sample but also an independent proposal of solutions, the possibility of action in conditions of high uncertainty and high complexity. The basis for the differentiation of levels is a set of indicators such as persistence and perseverance in goals' achieving, communication skills, a high standard of conduct, self-regulation, motivation, etc.

\subsection{The model of formation of design abilities during independent work of the student}

The author's model of design abilities' formation include target, theoretical, substantive, organizational and result units (Table 1).

The target unit of the model includes the idea of forming the students' design abilities through self-study to ensure their high competitiveness.

Theoretical model unit combines methodological approaches and principles designed to define the basis of the organization of students' independent project work.

Table 1. The model of design abilities' formation during independent work of the student

\begin{tabular}{|c|c|c|c|c|c|}
\hline TARGET UNIT & \multicolumn{2}{|c|}{$\begin{array}{l}\text { Purpose: formation of the design } \\
\text { abilities of students }\end{array}$} & \multicolumn{3}{|c|}{$\begin{array}{l}\text { Objectives: } \\
\text { 1) Subject training; } \\
\text { 2) Organization of independent work of students; } \\
\text { 3) Development of design abilities }\end{array}$} \\
\hline THEORETICAL UNIT & \multicolumn{2}{|c|}{$\begin{array}{l}\text { Approaches: competency, acme } \\
\text { logical, binary }\end{array}$} & \multicolumn{3}{|c|}{$\begin{array}{l}\text { Principles: scientific learning, novelty, temporality, the productivity of the } \\
\text { project, cooperation }\end{array}$} \\
\hline \multirow[t]{5}{*}{ ORGANIZATIONAL UNIT } & \multicolumn{5}{|c|}{ Plan of students' project activity } \\
\hline & 1 course & Theoretical project & reproductive, partially search & subject & individual \\
\hline & 2 course & theoretical & search & subject & Group \\
\hline & 3 course & Experimental project & search, creative & \begin{tabular}{|l} 
Inter \\
subject
\end{tabular} & Group \\
\hline & 4 course & Theoretical & research & integrativ & individual \\
\hline
\end{tabular}




\begin{tabular}{|c|c|c|c|c|}
\hline \multirow{2}{*}{ SUBSTANTIVE UNIT } & \multicolumn{2}{|c|}{ experimental } & & \\
\hline & $\begin{array}{l}\text { Pedagogical } \\
\text { support }\end{array}$ & \multicolumn{2}{|c|}{ means of training } & Kind of activity \\
\hline & Guided stage & \multicolumn{2}{|c|}{ An independent study of the course material +additional tasks } & reproductive \\
\hline & Oriented stage & \multicolumn{2}{|c|}{$\begin{array}{l}\text { Independent study of partially unfamiliar material +additional tasks + training } \\
\text { and project work }\end{array}$} & heuristic \\
\hline & Directed stage & \multicolumn{2}{|c|}{$\begin{array}{l}\text { Independent study of partially unfamiliar material +additional tasks + } \\
\text { independent search training and project work }\end{array}$} & Creative \\
\hline RESULT UNIT & \multicolumn{2}{|l|}{$\begin{array}{l}\text { Components: } \\
\text { problem-practical } \\
\text { content-practical } \\
\text { operational } \\
\text { reflexive }\end{array}$} & $\begin{array}{l}\text { Levels: } \\
\text { reproductive } \\
\text { heuristic } \\
\text { creative }\end{array}$ & \\
\hline
\end{tabular}

Organizational model unit specifies the plan of design abilities' development in the course of independent work of students, depending on the apprenticeship, the level of available knowledge, possibilities of the educational process.

In this paper is proposed to use the students' design work to almost all the subjects according to the unified requirements, so as to enable the student to determine their own direction of design in accordance with his or her interests.

A substantial block of the model demonstrates the idea of projects' organizing depending on the resources of students, types of activity, the degree of participation of the teacher. This differentiated approach is aimed at achieving the learning objectives for each student, the possibility of constructing a trajectory of learning and development.

Result unit contains the components and levels of development of students' design abilities placed by the teacher in the main stages of project evaluation. General summary of the design abilities' development can be summed by means of a summative evaluation of project performance across all disciplines in the training period.

\subsection{Pilot implementation of a model of design abilities' development into the university students' educational activity}

Implementation of the model requires that the following organizational-pedagogical conditions contributing to the formation of the students' design abilities should be taken into account:

1) the readiness of university teachers to organize the students' project activities from the view point of methodological and organizational positions;

2) creation of the system of students' design activity during the entire course of study at the University;

3) creation of educational- methodical and environmental components of students' project work;

4) formation of students ' motivation to self-project activities that contribute to their involvement.

An experimental implementation of the developed design model within the preparation of the students on specialty "Management of organization" in Kazan national research technical University was conducted.

When designing educational activities, educational plans and curricula for the project activities' organization the disciplines of Humanities, mathematics and the economic cycle were involved, designed to form the professional and cultural competence of the general scientific picture of the world, subject (special) competence. A system of project was developed on the entire period of study, implemented in the framework of teaching and students' independent work. The projects were carried out within the framework of one or several disciplines, depending on the chosen topic and area of tasks in individual and group form, depending on the scale of the tasks. As a result of integrated projects a single worldview, professional and personal competence in various fields were formed in students.

In the course of the study the experimental verification of the effectiveness of the developed model was carried out.

Dynamic's analysis of developments' levels of students' design abilities in the course of experimental work conducting on the use of the developed model showed that the results in the control (without change in the course of the educational process) and experimental groups (with projects' system implementation in independent work) are significantly different. The comparative analysis allowed state the improvement in experimental groups of students' number with creative level of design abilities by $17.8 \%$, while in the control groups it was $4.8 \%$. Students with a heuristic level of design abilities in the experimental group were more than $34 \%$. The number of trainees with reproductive level decreased in experimental groups by $48.5 \%$ and in the control groups by $8.7 \%$.

The obtained data of experimental work confirm that projects' system implementation in students' independent work during learning activities in the University has a significant impact on the formation of project ability, which means that it has the same impact on personal qualities and professional competencies' formation of a competitive specialist. 


\section{Discussions}

Independent work contributes to the deepening and expansion of students' knowledge, the formation of interest in learning activities, mastering of the techniques in design and evaluation methods and project management. This is inseparably connected with the formation of students' project ability and readiness to self-design of subject and social projects. Independent activity when responsibility for implementation and achievement of project goals belongs not only to one student trains students for future professional and social activities, contributes to the formation of professional and personality.

Project technologies are widely used in the professional training, along with active learning methods, extracurricular activities, however, the system of projects studied in detail by the authors from the theoretical, organizational, content, and technological positions have not previously been implemented in the educational process.

\section{Conclusions}

Thus, the developed model of formation of students' design abilities allows significantly intensify the educational process, to organize independent work of students, to develop personal and professional qualities of university students.

The result of applying of the model in the educational process gives a new level of students' design abilities, effectively forming specialists' professional and personal competence, providing their high competitiveness. The students' design skills and a high level of independence contribute to personal and professional growth of students, allow enhance and implement the knowledge obtained, facilitate the search for and construction of new ideas and give the development for professional creativity.

\section{Acknowledgments}

The authors thank all participants of this study for their kind cooperation.

\section{References}

Abulkhanova-Slavskaya, K. A. (2001). The problem of the subject definition in psychology. Science Press, 281.

Ananyev, B. G. (2001). A person as an object of cognition. Wallenberg Press, 158.

Andreev, V. I. (2003). Training for creative self-development. Centre for Innovative Technologies Press, 603.

Babanskii, J. K. (1995). Theoretical study. System optimization of training methods. Graduate School Press, 198.

Baidenko, V. I. (2004). Competence: competence-based approach to development. Journal of Higher Education, 11, 3-14.

Bodalev, A. A. (2002). On objective and subjective factors determining the achievement of acme by a person. Journal of "The world of education - education in the world", 4, 17-23.

Derkach, A. A. (2000). Psychology: personal and professional development of the individual. RAGS Press, 299.

Kagan, M. S. (1998). Philosophy of culture. Press DOE, 448.

Khutorskoy, A. V. (2003). Key competences. Technology design. Education Press, 416.

Kolesnikova, I. A. \& Gorchakova-Sibirskaya, M. P. (2005). Instructional Design. Academy Press, 288.

Kraevski, V. V. (2003). Pedagogy and its methodology I was yesterday and today. Internet magazine "Eidos". http://www.eidos.ru/ journal/2003/0711-03.htm.

Matyash, N. V. \& Volodina Yu. A. (2011). Methods of assessing the competence of students of design. Journal of Psychological research, 3, 212-238.

Pidcasisty, P. I. (2005). Organization of educational and cognitive activity of students. Russian Pedagogical Society Press, 144.

Retivikh, M. V. (2003). Psycho-pedagogical problems of modern education. Journal of the Bryansk Institute of Teacher Training, 1, 3-4.

Slastenin, V. A., Isaev I. F. \& Shiyanov E. N. (2002). Manual for students of higher educational institutions. Academy Press, 576.

Telegina, N. V. (2013). A binary approach to the control and optimization of diagnostic functions in the training of students 'general pedagogy'. Abstract of dissertation for the degree of Candidate of Pedagogical Sciences, 23.

Zimnya, I. A. (2006). Competence approach. What is its place in the modern approaches to education? (Theoretical and methodological aspect). Journal of Higher education today, 8(29). 